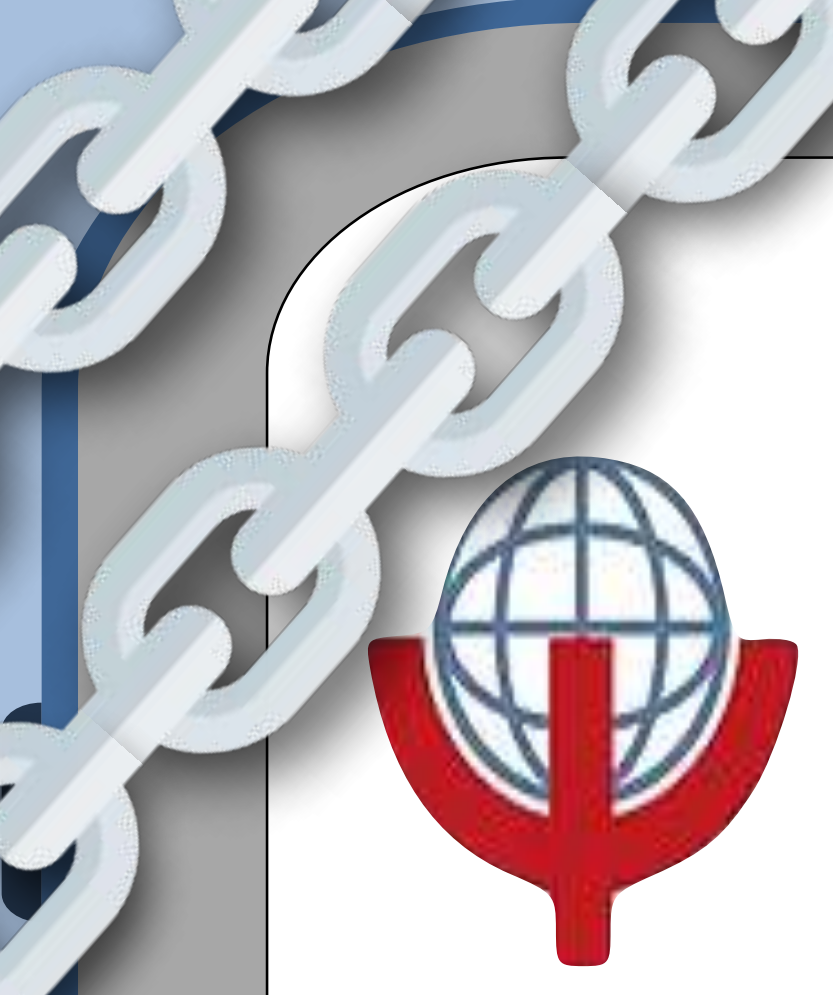

\title{
EVALUATING DIGITAL
} INTERVENTIONS FOR SMARTPHONE ADDICTION

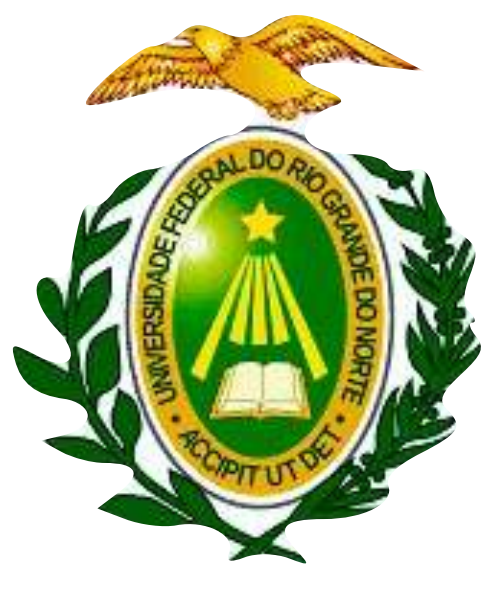

\author{
M E I R A - L I M A I . V., VELLOSO R.N. \\ DEPARTMENT OF CLINICAL MEDICINE \\ FEDERAL UNIVERSITY OF RIO GRANDE DO NORTE - UFRN
}

\section{B ACKGROUND} NATAL/RN - BRAZIL

Smartphone addiction affects populations all around the world. Its occurrence interferes with sleep, attention, memory, mood and relationships. The control of such condition has to be effective. For this reason, we seek to understand the digital strategies currently available.

\section{Method}

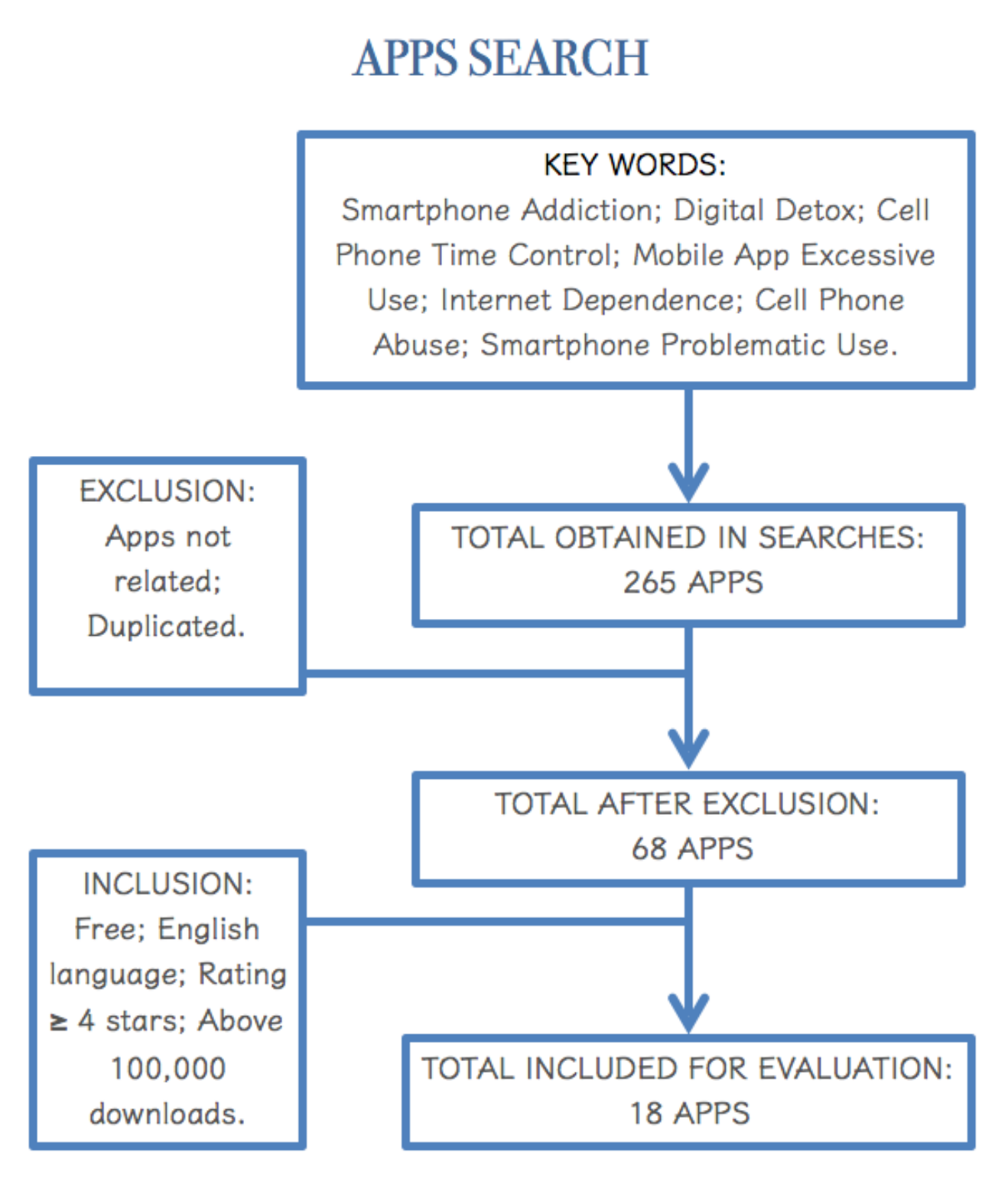

\section{Conclusions}

\section{OBjectives}

An increasing number of apps have been developed to help people with mental health issues. In this study, we propose a systematic review of apps designed for 'smartphone addition', in order to identify their strategies and clinical evidence of their efficacy.

\section{RESULTS}

\begin{tabular}{|c|c|c|c|c|c|c|}
\hline $\mathrm{N}$ & APP NAME & APP DEVELOPER & DOWNLOADS & RATING/ REVIEWS* & UPDATE* & SYSTEM \\
\hline 1 & Forest & Seekrtech, Taiwan & $5.000 .000+$ & 4,4/99.451 & April 27, 2019 & And. 4.4 \\
\hline 2 & UBhind & RinaSoft, South Korea & $1.000 .000+$ & $4,2 / 31.291$ & April 26, 2019 & And. 4.4 \\
\hline 3 & SPACE & SPACE Team, United Kingdom & $1.000 .000+$ & $4,2 / 26.386$ & January 18,2019 & And. 4.0 \\
\hline 4 & AppBlock & MobileSoft s.ro.,, Czech Republic & $1.000 .000+$ & $4,2 / 15.727$ & April 11, 2019 & And. 4,1 \\
\hline 5 & OFFTIME & mINdCUBEd, Spain & $1.000 .000+$ & $4,0 / 15.704$ & April 25, 2017 & And. 4.0 \\
\hline 6 & QualityTime & NComputing Global, Inc, United States & $1.000 .000+$ & $4,1 / 14.110$ & April 10, 2019 & And. 4.0 .3 \\
\hline 7 & Stay Focused & Innoxapps, India & $500.000+$ & $4,5 / 13.303$ & January 10, 2019 & And. 4,1 \\
\hline 8 & YourHour & Mindefy Labs, India & $500.000+$ & $4,5 / 12.511$ & April 15, 2019 & And. 5.0 \\
\hline 9 & Sma-Phospital & Fuller, Inc., Japan & $500.000+$ & $4,1 / 2.157$ & April 22, 2019 & And. 5.0 \\
\hline 10 & App Usage & Sam Lu, Taiwan & $500.000+$ & $4,3 / 5.559$ & April 19, 2019 & And. 4,1 \\
\hline 11 & AntiSocial & Bugbean Pty Ltd, Australia & $500.000+$ & $4,2 / 5.599$ & April 18, 2019 & And. 4.1 \\
\hline 12 & StayFree & Burak Kuyucu, Turkey & $100.000+$ & $4,6 / 12.282$ & April 22, 2019 & And. 5.0 \\
\hline 13 & Moment & Moment health inc. United States & $100.000+$ & $4,5 / 10.600$ & April 16, 2019 & iOs 11.2 \\
\hline 14 & Detox & For Innovation, Australia & $100.000+$ & $4,4 / 5.493$ & April 17, 2019 & And. 4.0 .3 \\
\hline 15 & Keep Me Out & Vikesh Dass, India & $100.000+$ & $4,3 / 3.413$ & October 2, 2018 & And. 4.0 \\
\hline 16 & Digital Detox & Urbandroid, Czech Republic & $100.000+$ & $4,4 / 2.874$ & April 17, 2019 & And. 5.0 \\
\hline 17 & AppDetox & AppDocs, Germany & $100.000+$ & $4,0 / 2.658$ & September 19, 2018 & And. 4,0 \\
\hline 18 & BlackOut & For Innovation, Australia & $100.000+$ & 4,2/1.484 & April 26, 2019 & And. 4.1 \\
\hline
\end{tabular}

INTERVENTION STRATEGIES

- INFORMING ABOUT USAGE PATTERNS • RAISING AWARENESS TO OVERUSE - RECOMMENDING BREAKS BLOCKING USAGE

- ENABLING SOCIAL COMPARISION ,APPLYING POSITIVE REINFORCEMENT

The review of the apps commercially available for 'smartphone addiction' demonstrates their popularity and their focus on encouraging phone blocks. However, there is a need for studies about clinical efficacy as well as the evaluation of novel approaches such relaxation techniques to control impulsive behaviours and measures to track the long-term progress.
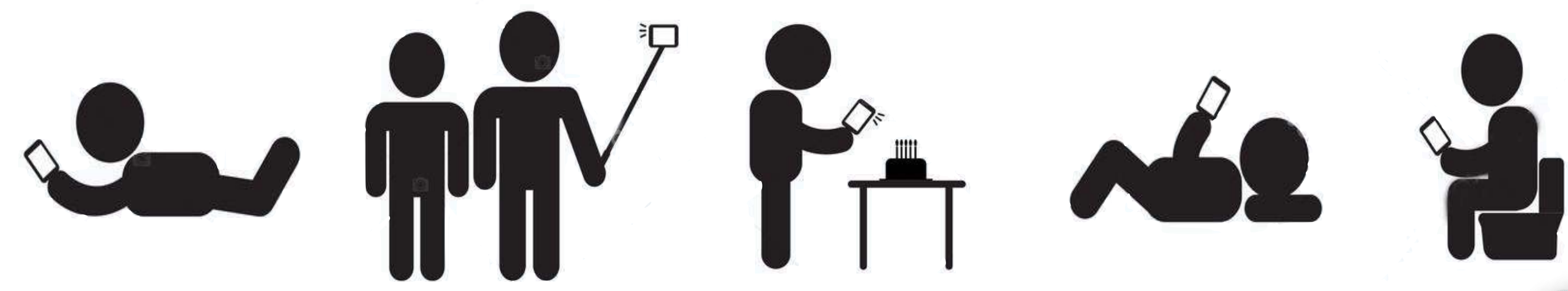